\title{
EL CONTRATO DE TRANSPORTE
}

Dr. Francisco de P. Restrepo Gutiérrez

\section{INTRODUCCION:}

El transporte es indudablemente uno de los temas juriaicos de mayor importancia que encontramos en el estudio del derecho comercial.

j:l análisis del transporte puede hacerse desde un punto de vista estrictamente jurídico, o por su aspecto económico. La importancia económica del transorte dentro de la actual estructuración social es un hecho tan protuberante, que sería cuando menos necio poner en tela de juicio el relevante papel que el transporte desempeña en el desarrollo de los pueblos. En el decurso de nuestro estudio nos limitaremos exclusivamente a ver el aspecto jurídico.

La intervención estatal en esta materia ha sido cada día más creciente. Podría afirmarse que no hay estado alguno que en una u otra forma, no haya intervenido de una manera directa en los transportes. Es quizá en este punto, donde más se ha manifestado la publicización del derecho comercial. En Colombia son innumerables, además de incoherentes, las normas estatales al respecto. Desde hace ya bastante tiempo, la empresa de transporte se encuentra entre nosotros francamente intervenida.

Claro que el Estado puede y debe intervenir para controlar no solamente la actividad del empresario de transportes sino la del empresario en general. Lo importante en este asunto es que la acción 
estatal no se dirija en beneficio exclusivo de determinadas empresas, porq:te todo privilegio en este sentido es desechable e injurídico.

Las numerosas normas de derecho público tendientes a regular la actividad de la empresa de transporte, no despojan a ésta de su carácter comercial, porque como anota Messineo al estudiar la institución de la empresa en el C. C. Italiano "no es que la empresa regulada por el código sea instituto de derecho público, si así fuere no se justificaría que el código la regulase, pasa solamente que las normas privadísticas relativas a la empresa, comprendidas en el código, no agotan su disciplina jurídica. La empresa sigue siendo un instituto privadístico, más como ella ejercita asímismo una función social hay que tener en cuenta también tal función, sólo así se le comprende integralmente; por eso la empresa también es gobernada por los principios publicísticos".

\section{IDEA HISTORICA DEL TRANSPORTE}

Aunque la noción del transporte es multisecular, el verdadero comercio del transporte y la aparición de las grandes empresas transportadoras, es un hecho que viene a cristalizarse con posterioridad a la E. M. Esto es explicable en el transporte de cosas, si tenemos en cuenta que durante la E. M. y con anterioridad a esta época el comerciante (remitente), personalmente o por medio de un representante, acompañaba sus mercancías del sitio desde donde debían desplazarse las cosas objeto del transporte hasta el lugar de su destino, no apareciendo entonces de una manera definitiva el complejo problema de la responsabilidad de la empresa de transportes, tal como hoy se le pretende estructurar. Actualmente el consignante (remitente, cargador) no tiene que escoltar las cosas transportadas, y aunque ello sucede el porteador siempre contrae una obligación fin y por lo tanto debe entregar las mercancías en el sitio de destino en el mismo estado en que las recibió. Por esto la justificación del art. 304, inc. $2^{\circ}$ de nuestro C. de C., es más que todo histórica.

Es a partir del siglo XIX, y con el surgimiento de las grandes empresas de transporte mundial, cuando esta industria adquiere trascendental importancia. A finas del siglo XIX, aparece una tendencia universal a las reglamentaciones uniformes internacionales por medio de tratados entre los diferentes estados, tendencia imperante sobre todo en el transporte ferroviario y de la navegación. (Convención de Berna de 1890).

\section{TEORICA CLASIFICACION DEL TRANSPORTE}

l'eúricamente hablando y atendiendo a la naturaleza de la ruta empleada, el transporte se puede dividir en terrestre, por vía acuática, yor el espacio y mixto.

El terrestre es, como su nombre mismo lo indica, el que se realiza por tierra. El transporte por vía acuática comprende el efectuado pcr mar, ríos, canales y lagos. El transporte por el espacio dice rela ión no sólo al que se cumple por el aire, (especie) sino que también comprende la explotación misma del espacio (género) por medio bién com diferentes máquinas utilizables al efecto. Hemos preferido en este punto no hablar de transporte aéreo, porque éste no es más que una parte del transporte que se puede realizar por el espacio. Por esto, La Comisión Revisora Del Código De Comercio en su exposición de notivos, acertadamente dice: "Nuestro país puede colocarse a la vanguardia legislativa, aprovechando que, como anota el citado Amvanguardia lla superaviación (estratosférica y de más allá) y la aviación interplanetaria, de la cual se habla hoy, impondrán quizás la revisión de cunceptos sustanciales corrientes, como así también de terminología. Se podrá, por ejemplo, hablar todavía de "navegación aérea" y de "aeromóvil", o sea de la máquina que, por reacción del aire, puede sustenerse en el espacio atmosférico, admitido que la técnica aviatoria tiende ahora a invadir espacios en los cuales el aire ya no existe nuás?"... Cómo podrán clasificarse y definirse jurídicamente las islas flotantes en el espacio, llamadas satélites artificiales de nuestro planeta, que se están ideando y se dice posible construir como bases para los vuelos a extremas alturas e interplanetarios?"... (1). De allí que en el proyecto haya reemplazado la comisión las expresiones corrientes de "aeronavegación" o "navegación aérea", y sus correlativas, por la más amplia de "aviación" (artículo 2016), que no limita la capacidad de desplazamiento a la sola atmósfera ni sugiere la suspensićn en los espacios por las reacciones del aire. Y que en vez de "aerumózil", haya utilizado en ocasiones la locución "máquina volante"... Una de las formas de usar un espacio es la "navegación aérea", esto es, aquella que se efectúa en el "espacio atmosférico" por medio de aeronaves, o sea, de máquinas volantes capaces de conducir personas o cosas de un lugar a otro de la atmósfera".

(1) Proyecto de Código de Comercio, Tomo II, Bogotá, Julio de 1958. Exposición de motivos. Del Libro Primero. Pág. 584. 
wl transporte mixto se presenta cuando se utilizan diferentes clases de transporte, como cuando un determinado viaje o conducción de objetos se efectúa por tierra y por agua.

En el transporte en general, se puede aún advertir cierta dicotomía entre el transporte de personas y el de cosas, sometidos muchas veres a diferentes normas, dadas sus diferencias.

El transporte tererstre y atendiendo al diverso grado de desarrollo de la humanidad, se ha realizado por diferentes medios. Realmente podemos distinguir desde el transporte ejecutado por el propio homore o por medio de animales, hasta el que se presta por los vehículos niás perfectos de nuestro tiempo.

Los diversos tipos de transporte y por razón de que cada uno de ellos presenta características propias, están sometidos a reglamentaciones diferentes, lo cual no impide que muchas normas sean de aplicación general para toda clase de transporte.

\section{CLASIFICACION DEL TRANSPORTE EN COLOMBIA}

Ja anterior división teórica del transporte no armoniza perfectamente con la que podemos hacer desde el punto de vista de nuestro derecho positivo actual.

In Colombia podemos distinguir el transporte terrestre, el marítinio y el aéreo.

Ll marítimo es el que se realiza por mar, y de él se ocupa el C. D. C. N. ('ódigo de comercio marítimo). El transporte terrestre entre nosotros comprende el que se verifica por tierra, canales, lagos o ríos navegables. El proyecto, con algunas excepciones, hace extensivas a la navegación fluvial las reglas relativas a la navegación marítima (2). Sobre el transporte aéreo existen en nuestro país algunas leyes y decretos, pero no una adecuada reglamentación positiva. Sobra anotar que en Colombia no hay, como tampoco existe en ningún país del intuado, una verdadera legislación del transporte por el espacio. El froyecto sí contempla esta clase de transporte.

\section{EL TRANSPORTE TERRESTRE}

\section{Campo de aplicación del C. D. C. T.}

Como de acuerdo con nuestro sistema legal el transporte terrestre también abarca, además del auténtico transporte por tierra, el

(2) Pruyecto de Código de Comercio. Tomo I. Artículo 2.007. que se presta por ciertas vías acuáticas, es necesario saber hasta donde llega en esta materia el campo de aplicación del C. D. C. T. y comienza el dominio del C. D. C. M. La solución del problema nos la da éste último código al expresar que el comercio marítimo comprende el comercio exterior de cabotaje y costanero de la Unión (3) Y agrega el mismo C. D. C. M. que "comercio de cabotaje es el que se hace entre dos puertos de la Unión habilitados para el comercio exterior, o en que hay establecidas aduanas; y comercio costanero o de cabotaje menor, el que se hace entre dos puertos no habilitados para el comercio exterior, o entre uno de éstos y otro de los primeros". (4).

Entrando ahora al estudio del transporte terrestre, regulado en el C. D. C. T. por los artículos 258 y siguientes bajo el título "Del Transporte por Tierra, Lagos, canales o ríos navegables", veamos en primer término su definición y hagamos un análisis de la misma.

\section{DEFINICION}

El código define el transporte como "un contrato, en virtud del cual uno se obliga por cierto precio a conducir de un lugar a otro, por tierra, canales, lagos o ríos navegables, pasajeros o mercaderías ajenas, y entregar éstas a la persona a quien vayan dirigidas". (5).

\section{Análisis de la definición}

Etimológicamente hablando por transporte debe entenderse la acción y el efecto de transportar, locución ésta que tiene su orígen en la voz latina "transportare", que significa desplazar o conducir algo de un lugar a otro.

Expresa la definición que el transporte es un contrato, esto es, un acuerdo de voluntades para producir efectos jurídicos, obligaciones. El contrato es un "ente jurídico" generador de obligaciones, su finalidad es ésta. Convención es término genérico, el contrato es la especie, y, como se ha dicho, la fuente más fecunda de las obligaciones. Es un acto jurídico de formación bilateral, plurilateral o multilateral, en contraposición a los actos jurídicos de formación unilateral como la simple oferta. Por lo tanto, el transporte es un contrato y como tal un "ente" creador de obligaciones. De él surgen, entre otras, las siguientes obligaciones: a). La de trasladar de una parte a

(3) C. D. C. M. Artículo 19

$(4)$ C. D. C. M. Art. $3^{9}$
C. D. C. T. Art. 258. 
otra pesajeros o cosas, la cual corresponde al transportista y es una obligación de hacer, puesto que dar jurídicamente significa transpasar dominio o constituír o traspasar un derecho eral, y todo hecho positivo que pueda servir de objeto a la obligación y que no constituya obligación de dar, representa una obligación de hacer. Es claro que la obligación de conducir no implica traspasar dominio o constituir o traspasar un derecho real, luego es obligación de hacer. b). El consignatario o el cargador, según el caso, se comprometen a pagar el porte o flete de la conducción, obligación ésta sí de dar, ya que conlleva traspaso de dominio.

El C. C. denomina al transporte "arrendamiento de transporte". (6). Por su parte, el C. D. C. T. asevera que "el transporte participa del arrendamiento de obra o de empresa y del depósito" (7). Nuestra ley, al igual que muchas legislaciones y autores, involucra el transporte con el arrendamiento y con el depósito, posición desde todo punto de vista insostenible como tendremos oportunidad de ver al estudiar la naturaleza jurídica del transporte.

Determina el C. D. C. T. al definir el contrato objeto de nuestro estudio que, al porteador se le pague "cierto precio" por la conducción. En la legislación colombiana es, pues, necesario la existencia de un determinado precio en el transporte.

El precio que viene a ser, según los expositores, la suma de dinero que el transportador tiene derecho a percibir por la conducción de pasajeros o cosas, dice siempre relación a una suma cierta de dinero. De allí que la ley civil al tratar de la compraventa manifieste que "El dinero que el comprador da por la cosa vendida, se llama precio" (8).

El precio, que debe ser determinado o determinable, se denomina también porte o flete, $\mathrm{y}$ se puede pactar en moneda nacional o extranjera. El transporte se puede realizar con porte pagado o con porte a cobrar. El flete universalmente se determina por una tarifa general atendiendo a la clase de transporte y a la distancia kilométrica. A veces y por razón de ciertas circunstancias especiales, existen portes más reducidos que los comunes, como ocurre en casos como los siguientes: a). Atendiendo al número de pasajeros, como en el transporte colectivo. b). Teniendo en cuenta la calidad de los viajeros, como cuando se trata de tarifas obreras, escolares y familias nume-

(6) C. C. Libro IV Título XXVI Capítulo X.

( 7 ) C. D. C. T. Art. 264. rosas. c). Otras veces por razón de la finalidad misma del transporte, como en los casos de congresos, peregrinaciones y excursiones.

En la venta denominada "CIF", el vendedor debe pagar el seguro y el flete de las cosas hasta el puerto o lugar de destino. Es ésta una venta marítima al embarque, que bien puede ser de aplicación general, y por medio de la cual el comprador se torna en propietario de los objetos transportados desde el momento en que las cosas han sido puestas a bordo. En francés se le denomina venta "CAF", expresión formada por las iniciales de las palabras: costo, seguro, flete (cout, assurance, fret), ya que la venta se hace por un precio global que comprende el valor de los objetos, el flete y la prima de seguro. En inglés recibe el nombre de venta "CIF" (cost, insurance, freight).

Existe también la venta "FOB", libre o franco a bordo, término compuesto por las iniciales de la frase inglesa FREE-ON-BOARD, en este caso el comprador debe pagar el flete, a diferencia de la venta "CIF" en la cual es el vendedor quien contrae la obligación de hacer transportar las cosas.

Habíamos visto que en nuestro sistema positivo se requiere la existencia de un "precio" en el transporte. Qué pasa, entonces, si se pacta que el porteador, en lugar de un "precio" determinado, tiene derecho a otra prestación distinta, por ejemplo, si se conviene que el transportista tiene derecho a una "cosa" determinada? Qué contrato habría? No parece que los principios generales del derecho se opongan al nacimiento de un contrato de transporte en esta hipótesis. Además, el hecho de que el transportador pueda obtener una prestación diferente de la de percibir un "precio", no podría servir de pretexto a las partes para eludir el cumplimiento de sus obligaciones,ni alteraría la esencia misma del contrato de transporte. En último caso, se trataría de un contrato innominado, al cual, por su similitud con el transporte, habría que aplicarle las reglas propias de éste. Naturalmente, lo normal es que la prestación a favor del porteador se pacte en dinero, mas el caso supuesto es perfectamente factible.

El proyecto que exige que se convenga un "precio", al definir el transporte como un contrato por medio del cual "una persona se obliga, a cambio de una prestación determinada, a conducir de un lugar a otro pasajeros o cosas...". (9). El C. C. Italiano tampoco ordena la presencia de un "precio", ya que según esta legislación por el contra:o de transporte "el porteador se obliga, mediante compensación a trasladar personas o cosas de un lugar a otro". (10).

(9) P. D. C. D. Art. 802

(10) C. C. Italiano. Art. 1678. 
El elemento primordial, que estructura y tipifica el contrato de transporte, viene a ser el hecho material de desplazar de un sitio a otro, pasajeros o cosas. Por esto dice el códico que el porteador se obliga "a conducir de un lugar a otro, pasajeros o mercaderías". (11).

El art. 258 alude a canales, lagos o ríos navegables. Como navegable debe entenderse para los efectos legales "todo trayecto fluvial que de una manera efectiva pueda servir o sirve habitualmente, durante la mayor parte del año, de vía de comunicación entre diversos lugares, cualesquiera que sean la clase y capacidad de las embarcaciones usuales en que se verifique o pueda verificarse el tránsito a lo largo de su curso, sea remontándolo o descendiéndolo". (12).

Al manifestar el código que el transportista se obliga a conducir pasajeros o mercaderías, está distinguiendo entre el transporte terrestre de personas y el de cosas, clasificación ésta que es común a toda clase de transporte. La reglamentación que tiene el C. D. C. T., a pesar de lo extensa, es muy deficiente y se refiere casi exclusivamente al transporte de cosas, el de personas está tratado superficialmente. $\mathrm{El}$ proyecto regula de una manera más perfecta, tanto el transporte de personas como el de cosas. Además de las normas que el C. D. C. T. contiene en relación con el transporte, existe en Colombia una basta reglamentación administrativa que ha tratado de organizar la empresa de transportes.

En armonía con la definición comentada, una persona, el porteador, se obliga a conducir "pasajeros o mercaderías". La expresión "mercaderías" debe entenderse aquí en un sentido amplio y no restringido, y abarca toda clase de "cosas" u "objetos" que son susceptibles de trasladarse de un paraje a otro. El proyecto y alguos códigos extranjeros como el Italiano, en vez de "mercaderías" se refieren a "cosas". (13). Como la locución "mercaderías" podría dar origen a cierta inexactitud, ya que algunos le dan un alcance muy restringido, nos parece mejor hablar de "cosas" o de "objetos" que pueden transportarse.

El objeto de transporte de cosas consiste en la conducción de bienes materiales muebles, porque sólo los muebles se pueden desplazar de un lugar a otro, un inmueble por naturaleza no podría ser transportado. Se transportan cosas de gran valor (alhajas), o cosas de poco valor, y puede ser objeto de este contrato hasta un vehículo que se carga en otro para efectos de locomoción.

(11) C. D. C. T. Art. 258.

(12) Decreto Leg. 1141 de 1932. Art. único.

(13) P. D. C. D. Art. 802. C. C. Italiano. Art. 1678.
Dice el C. D. C. T. en el artículo que estamos examinando que, el porteador se obliga a conducir pasajeros o "mercaderías ajenas", es decir, estatuye la referida norma legal que, las cosas materia del desplazamiento no pueden pertenecer al mismo transporteador, deben ser de otra persona. No obstante, podríamos preguntarnos: será indispensable, requisito sine qua non, esencial al transporte, que los objetos que se conducen sean de una persona diferente a la del transportador? Esto es, si se trata de cosas propias diel porteador, no podría existir contrato de transporte? La cuestión ha sido un tanto debatida. Quienes opinan que las cosas deben ser ajenas se apoyan, entre otras, en las siguientes razones: a) - Siendo el transportista el dueño de los objetos transportados no habría porte ya que el propio portador no podría cobrarse asimismo el flete, y éste es uno de los ingredientes necesarios en el transporte como posteriormente se verá. b) - El transporte es un contrato y, por ende, reclama un acuerdo de voluntades, en la hipótesis de que el transportador sea el dueño de las cosas, éste no tendría con quien contratar, no habría el acuerdo de voluntades obligatorio en todo contrato. Los que así piensan, estiman que en este supuesto no hay más que una persona, la del porteador, y como el transporte como contrato exige la concurrencia mínima de dos voluntades, optan por la negativa.

Sin embargo no parece absurdo sostener que puede haber transporte aún en el caso de que las cosas sean del transportador. En favor de esta tesis, se han puesto ejemplos como el siguiente: A., quien reside en Medellín y es un transportador, tiene unas mercancías en esta ciudad para la venta. B., residente en Barranquilla, se interesa en dichas mercancías. Entre A. y B. se celebra un contrato de opción en virtud del cual A., oferente o prometiente, se obliga para con B. a venderle, dentro de un plazo expresamente determinado, las mercancías en relación, si $\mathrm{B}$. dentro del término que tiene y después de un examen detallado de las cosas opta por comprarlas. Como A. es un transportador, además del pacto anterior, convienen las partes en que el propio A. se obligue, por cierto precio, para con B. a trasladarle las mercancías a Barranquilla para que el interesado las examine. Si B. decide no hacer ninguna compra, a lo cual lógicamente no está obligado, pagará a A., de acuerdo con lo pactado, el porte de la conducción.

Haciendo a un lado el contrato de opción que se ha llevado a cabo, hay también en el ejemplo dado un contrato de transporte, ya que se ha estipulado un flete como contraprestación por el transporte, estando A. indudablemente forzado a verificar el traslado de sus 
propias mercancías. Qué ocurre si luego de que A. ha desplazado los objetos al lugar de su destino, B. se niega, por una parte, a comprar las cosas y por otra, a pagar la contraprestación por la conducción? En cuanto a lo primero, cuestión ajena al contrato de transporte, no hay problema alguno, puesto que B. tenía una opción y bien podía o no comprar. En cuanto a lo segundo, naturalmente que A. tendrá acción contra B. por el porte, acción que nace precisamente de la violación del contrato de transporte celebrado, y no de ninguna otra relación contractual o extracontractual entre las partes.

El proyecto, como habíamos expresado, manifiesta que en el transporte, una persona se obliga a conducir pasajeros o cosas, no exigiendo que éstas sean ajenas y dando así cabida a la opinión últimamente sostenida. Lo mismo existe en la legislación Italiana.

El porteador se obliga, de acuerdo con el texto analizado in fine, a entregar las mercaderías "a la persona a quien vayan dirigidas", es decir, al consignatario o destinatario.

Después de haber examinado la definición que del contrato de transporte trae el C. D. C. T. y haber criticado ciertos aspectos de la misma, podemos definir este contrato, como aquél por medio del cual una persona, denominada antiguamente acarreador, y actualmente transportador, se obliga, por una determinada contraprestación a trasladar o conducir de una parte a otra, personas o cosas, y entregar éstas en el sitio convenido, al destinatario.

\section{EL CONTRATO DE MUDANZA}

Este contrato es una especie de transporte y en virtudd e él una parte, el porteador, se obliga para con otra, por una determinada contraprestación, a embalar, conducir y acomodar una pluralidad de cosas muebles, generalmente destinadas al amueblamiento de edificios $\checkmark$ casas de habitación. Esta convención impone al transportador determinadas obligaciones que en principio no son propias del transporte común de cosas del cual es una especie la "mudanza", como las de embalar los objetos frágiles, colocar y armar y desarmar los objetos conducidos. Es lo que ocurre generalmente cuando una persona se traslada de una habitación a otra y estipula con un transportista la conducción de sus muebles.

Aunque algunos han pretendido negar en este caso la existencia de un transporte, no aparece por parte alguna un fundamento sólido para quitarle a esta estipulación su estructuración típica de transporte. El hecho de que en esta hipótesis aparezcan elementos preparatorios o consiguientes al transporte, no es basamento eficiente, como piensan ciertos autores, para aseverar en tal supuesto el nacimiento de un contrato diferente, ya que en la "mudanza" se reunen todos los elementos integrantes del transporte. Por otra parte, aún admitiéndose que este contrato sea innominado y diverso del transporte, por la semejanza que guarda con éste último deberá someterse a las normas propias del mismo.

La jurisprudencia Francesa no concede en estos casos al transportista el derecho de retención, para proteger al cliente del empresario de mudanzas, sobre todo por la naturaleza misma de los objetos transportados, generalmente cosas indispensables diariamente en el hogar como instrumentos de cocina, muebles, etc.

El transporte postal de paquetes y el que tiene por objeto noticias por medio de correspondencia, son figuras jurídicas en las cuales se reunen todos los requisitos necesarios para la existencia de un auténtico transporte, pero son servicios públicos que universalmente se prestan directamente por el estado mediante el pago de una tarifa de carácter general, y en los cuales lógicamente impera una reglamentación de estricto derecho público.

\section{FIGURAS PARECIDAS AL TRANSPORTE}

La transmisión de noticias por telégrafo y la comunicación de las mismas por teléfono, que son también servicios públicos prestados exclusivamente por el estado, son figuras jurídicas parecidas al transporte, pero no reunen las condiciones indispensables para el nacimiento de éste. En efecto, la traslación de un objeto material de un lugar a otro, elemento fundamental en el trasporte de cosas, no existe en la transmisión de noticias por telégrafo ni en la comunicación de las mismas por teléfono. En el transporte "hay conducción de un bien material (o de una persona), de un lugar a otro. El hecho de que la oficina telegráfica transmita una noticia al destinatario, por encargo del remitente, no implica ningún desplazamiento de bien material (módulo o impreso sobre el cual el remitente ha extendido el telegrama); y el hecho de que el usuario se valga del aparato telefónico puesto a su disposición por el gestor del servicio, implica transmisión de sonido, de un lugar a otro, pero no desplazamiento material de cosa". (14). Estos casos han sido tratados, por unos autores, Francisco Messineo, Manuale Di Diritto Civile e Comerciale, traduc-
ción de Santiago Sentis Melendo - Buenos Aires 1956. Tomo V. Pag. 213. 
como una forma particular de prestación de obra o de servicio, por otros, como una institución innominada.

\section{TRASPORTE BENEVOLO}

El transporte benévolo surge como consecuencia de un servicio gratuito, de un acto de liberalidad, o como dicen los expositores, "de la dispensa de una atención, de un acto de deferencia o de mera cortesía en el transporte", pues no existe entonces ánimo de contraer vínculo contractual ni contraprestación de ninguna naturaleza. Es el caso de un conductor que viajando en su automotor con dirección a determinado sitio se encuentra con una persona que espera un vehículo para ir al mismo lugar, y por mera cortesía, por simple favor y sin contraprestación alguna, ofrece sus servicios a quien impacientemente desea trasladarse, y efectivamente lo invita y lo conduce al paraje ambicionado. Habrá en esta hipótesis contrato de transporte? Parece que no. En consecuencia con la generalidad de las legislaciones y la gran mayoría de la doctrina y de los expositores, el transporte es un contrato oneroso. En el ejemplo puesto nos encontramos en presencia de un acto gratuito, luego no se trata de un contrato de transporte. La conducción complaciente no encaja, pues, dentro del género de los actos jurídicos a título oneroso, sino dentro de la categoría de los actos gratuitos.

Por lo expuesto muchos autores y aún la misma jurisprudencia, han ocnsiderado que en el transporte benévolo no hay relación contractual de ninguna índole, y que, por ende no existe un contrato de transporte. Por esto se ha creído que en tal caso solo hay una situación potestativa. El conductor generoso no ha pretendido contraer ningún nexo jurídico, no existe ánimo contrahendi obligationi. Quien así ha obradio, solamente ha querido efectuar un acto de cortesía, de pura liberalidad, mas no contraer obligaciones. En el auténtico contrato de transporte, las partes han tenido el ánimo de obligarse, cuestión que no ocurre en el transporte benévolo.

No es, pues, factible invocar una responsabilidad contractual en tratándose de un transporte benévolo. Claro que en tal hipótesis si pueden nacer obligaciones, pero no como consecuencia de un contrato de transporte, sino como corolario de una responsabilidad extracontractual, es decir, de una responsabilidad que no tiene orígen en la violación de un contrato, porque aún en el ámbito de las relaciones gratuitas quien por dolo o culpa o de cualquiera otra forma ha ocasionado perjuicio a otra persona, es obligado a la indemnización, sin perjuicio de la respectiva acción penal, cuando a ella hubiese lugar; como acontecería en el supuesto del conductor complaciente (trasporte benévolo) que culposamente se accidenta y lesiona al pasajero.

Es de advertir que muchos autores, con Demogue a la cabeza, impugnan la distinción de naturaleza entre la responsabilidad contractual y la extracontractual. Tal división ha sido relevada por el mencionado autor, entre otros, por aquella otra que clasifica las obligaciones en cuanto al contenido de las mismas, en dos, a saber: a) Obligaciones determinadas y precisas, de resultado o de fin. b) Obligaciones generales de prudencia y diligencia, u obligaciones de medio. La diferencia de las obligaciones en cuanto al contenido de las mismas sería de operancia general, esto es, abarcaría tanto el campo contractual como el extracontractual. Posteriormente veremos a quién incumbe la carga de la prueba en cada una de estas obligaciones.

Aunque la división de las obligaciones por su contenido ha sido sin duda una gran conquista del derecho, es innegable la diferencia de origen entre las responsabilidades comentadas. La contractual emana de la inejecución de un contrato, caso en el cual operan las reglas pertinentes de los contratos. La responsabilidad delictual nace con independencia de todo vínculo contractual, y se rige por las normas de la responsabilidad extracontractual. Por la diferencia apuntada, es decir, por su diversidad de fuente, las accioens que se derivan de las aludidas responsabilidades, no pueden ejercerse simultáneamente, no es dable su acumulación.

A la luz del actual C. D. C. T., el transporte benévolo no es un verdadero transporte, pues como habíamos dicho al estudiar la definición de este contrato, nuestra ley manda que se estipule "cierto precio" por la conducción. En el transporte benévolo lo que sucede es la prestación de un servicio gratuito, sin contraprestación alguna.

De acuerdo con el P. D. C. D. C., el transporte benévolo tampoco es un contrato de transporte, por dos razones: a) Ordena el relacionado estatuto que, al porteador se le debe pagar una suma de dinero u otra prestación lícita cualquiera por el desplazamiento. (15). En el transporte benévolo, como repetidas veces hemos expresado, no existe contraprestación a favor del semi-porteador; b) El P. D. C. D. C. soluciona terminantemente el problema, al manifestar que, "el transporte benévolo o a título gratuito no se tendrá como contrato mercantil sino como sea accesorio de un acto de comercio". (16).

(15) P. D. C. D. C. Art. 802

(16) P. D. C. D. C. Art. 802 
No obstante las conclusiones anteriores, es conveniente recordar que ciertos autores admiten la posibilidad de un contrato de transporte gratuito. Estasén, por ejemplo, afiram en su libro "Instituciones de Derecho Mercantil" que, "el transporte gratuito no supone más que la renuncia del derecho a cobrar el precio, pero esto no modifica el contrato de transporte". A pesar de la fuerza que pueda tener la tesis de Estasén, no la compartimos, y no nos adherimos a ella, además de los argumentos anteriormente expuestos y que serían suficientes para ello, por las consideraciones siguientes: Con la misma lógica de Estasén, se podría aseverar la existencia de una compraventa gratuita, es decir, en la cual el comprador no tuviera la obligación de pagar el precio de la cosa objeto de la compraventa, ya que en este caso no habría más que la renuncia del derecho a cobrar el precio de la cosa, sin que por esto la compraventa perdiese su naturaleza de tal, ni sufriese modificaciones en su misma esencia, esto es, sin que dejase de ser compraventa. Sin embargo, a nadie se le ha ocurrido pensar que una compraventa sin precio, sería compraventa. Lo que pasa realmente es que en esta hipótesis no hay tal renuncia al derecho de cobrar el precio; lo que existe es un acto gratuito, de mera liberalidad, una donación. Con la argumentación del referido expositor, no habría actos gratuitos en derecho, no existiría la donación, porque en ésta habría siempre una renuncia de parte del donante, para no exigir del donatario el cumplimiento de una determinada contraprestación, existiría entonces, según Estasén, una compraventa una permuta $u$ otro contrato, mas no donación.

Es un hecho indiscutible que, en la compraventa el precio es de la esencia del contrato, essentialia negotii. Cosa similar pasa en el transporte, en donde la contraprestación que se paga por el desplazamiento, es requisito sine qua non, necesario para la estructuración del mismo.

Por otra parte, un contrato de transporte gratuito iría directamente contra uno de los principios generales del derecho mercantil, el ánimo especulativo, que si bien a veces no se presenta en determinadas relaciones comerciales, sí es la regla general.

\section{UBICACION DEL TRANSPORTE DENTRO DE LA CLASIFICACION GENERAL DE LOS CONTRATOS}

En este punto y sobre todo por razones prácticas, prescindiremos de clasificaciones técnicas tan importantes como aquella que distingue entre los contratos de enajenación, de uso, de prestación de ser- vicios, de gestion de negocios ajenos y de gestión colectiva, para seguir, en principio, las huellas seguidas por la legislación Colombiana sobre la materia.

Según las obligaciones que producen, los contratos se han dividido en "unilaterales" y "bilaterales". Los primeros son aquéllos que en el momento de su celebración sólo generan obligaciones para una de las partes. Los bilaterales, o sinalagmáticos para el C. C. Francés, desde su celebración producen obligaciones recíprocas para todas las partes contratantes. Estas, como dice el C. C., "se obligan recíprocamente". (17).

No pocos expositores, siguiendo el derecho romano, hablan de contratos "sinalagmáticos perfectos" e "imperfectos". Los sinalagmáticos perfectos son precisamente los contratos bilaterales. Los segundos son aquellos que en el momento de su celebración sólo generan obligaciones para una de las partes, es decir, son unilaterales; pero posteriormente y en virtud de hechos contingentes y accidentales que no pertenecen realmente a la naturaleza del acto, pueden producir obligaciones para la parte que en un principio no se obligó. La subdivisión anterior no ha sido, sin embargo, aceptada por ciertos autores que, como Planiol, no le ven utilidad ni razón de ser.

Atendiendo a la distinción en mención, el transporte es un contrato bilaterial, porque de él nacen obligaciones y derechos recíprocos para las partes, desde el momento mismo de su celebración. Así, en el transporte de cosas el remitente (o el destinatario) contrae la obligación de pagar el flete, el porteador recíprocamente la de conducir.

El estudio de las obligaciones que nacen del transporte, serán objeto de un análisis especial.

Según la utilidad que derivan las partes, los contratos se dividen en "interesados" u "onerosos" y "gratuitos". El contrato es oneroso, si las partes se gravan en beneficio recíproco. Es gratuito, "cuando sólo tiene por objeto la utilidad de una de las partes, sufriendo la otra el gravamen" (18). Los contratos gratuitos, generalmente "intuituu personae", se pueden clasificar en, los de "beneficencia" y los que conllevan verdaderas "liberalidades". En los primeros, por ejemplo el mutuo sin interés, el contratante que otorga la utilidad a la otra parte, no sufre en realidad ninguna merma en su patrimonio. En los segundos, como ocurre en la donación, sí hay una disminución patri(18) C. C. Art. 1496. 
monial, la del donante, armónica con el incremento patrimonial de otra parte, el donatario.

La referida clasificación, es de trascendencia no sólo en el cam. po del derecho civil, sino también en la esfera de las relaciones co merciales. Por ejemplo, el transporte gratuito, como observamos, no origina responsabilidad contractual, el oneroso sí. Por su parte, el decreto de quiebras al tratar sobre la anulabilidad de los actos del quebrado, distingue entre los actos a título gratuito y los onerosos. (19) Asimismo, en los actos de comercio y en general en todas las situaciones mercantiles, la regla es la onerosidad, la excepción la gratuidad.

El transporte es, desde luego, un contrato oneroso. Desde el pun to de vista de la doctrina y de nuestra legislación, esta afirmación es incuestionable.

El contrato oneroso se subdivide a su vez en conmutativo y aleatorio. En el conmutativo "y desde la formación del contrato, las prestaciones son ciertas, conocidas y firmes y por eso se reputan equivalentes" (20). El C. C. dice al respecto que, el contrato oneroso es conmutativo "cuando cada una de las partes se obliga a dar o hacer una cosa que se mira como equivalente a lo que la otra parte debe dar o hacer a su vez". (21).

La definición del C. C. es, a nuestro juicio, incompleta. Porque para el código el contrato es conmutativo sólo cuando se trata de obligaciones de "dar" o de "hacer", esto es, excluye las de "no hacer". Pero si una de las partes se obliga a "dar" y la otra a "no hacer", el contrato también puede ser conmutativo, no habría la más mínima razón para sostener lo contrario. Lo que distingue el contrato conmutativo es precisamente el hecho de que las prestaciones por ser "ciertas, conocidas y firmes se reputan equivalentes", pero no la circunstancia de que se trate de obligaciones de "dar" o de "hacer".

El contrato es aleatorio, por oposición al conmutativo, cuando una de las prestaciones "consiste en una contingencia incierta de ganancia o pérdida" (22), como el juego y la apuesta.

En armonía con la relacionada subdivisión el transporte es en principio un contrato conmutativo.

Por razón de su nacimiento y subsistencia, los contratos se clacifican en principales y accesorios. El principal tiene una existencia

(19) Decreto 750 de 1940. Art. 36

(20) Prof. Eudoro González G. Revista Estudios de Derecho NQ 38. Pág. 188. (21) C. C. Art. 1498

(22, C. C. Art. 1498 independiente y "subsiste por sí mismo sin necesidad de otra convención" (23). El accesorio requiere la existencia de una obligación principal, sin la cual no puede subsistir.

Teniendo el transporte vida autónoma y no siendo su finalidad la de asegurar el cumplimiento de una obligación principal, salta a la vista el carácter principal de este contrato.

Los contratos, según hayan sido o no identificados por la ley con nombre especial, se han dividido en "típicos" o "nominados" y "atípicos" o "innominados". Esta distinción tuvo trascendencia en épocas pretéritas, cuando era menester que los contratos encajaran perfectamente dentro de los tipos expresamente regulados por la ley. Actualmente y en virtud del principio de la "libertad contractual", tal clasificación carece de relevancia jurídica, pues los contratos aunque no se amolden a los tipos legales, son siempre valederos, desde que sean lícitos.

El transporte, es naturalmente un contrato típico. La ley lo ha bautizado con un nombre especial.

También se ha distinguido entre los contratos de goce o "ejecución instantánea" y los de "ejecución" o "tracto" "sucesivo", "continuo", "duradero" o "diferido", "tractu tempore". En los instantáneos las presetaciones de los contratantes se cumplen en un moemnto dado, no se renuevan en el tiempo, se extinguen en un preciso instante. En los contratos tractu tempore las prestaciones de las partes, o al menos algunas de ellas, se repiten en el tiempo, sus efectos se renuevan constantemente y por eso se cumplen en un lapso más o menos largo.

Tratándose de contratos de ejecución diferida no se puede hablar propiamente de "rescisión" (tampoco de resolución), porque ésta como producto de la nulidad relativa es un vicio que requiere decisión judicial, y una vez declarada, restituye las cosas al estado que tenían antes de la celebración del contrato, todo queda como si nada hubiese pasadio.

Los contratos de tracto sucesivo, como producen ciertos efectos cumplidos en ejecución del convenio que no podrían borrarse y ser desconocidos, no se rescinden; la expresión jurídica adecuada es entonces "terminación", "expiración" o "cesación", la cual opera únicamente para el futuro, "ex nunc", no para el pasado. Las cosas, no pueden, pues, volver a la situación en que las partes estaban antes (23) 
de la realización del acto, ni es necesaria la declaración judicial. Co mo ejemplo típico de estos contratos se ha puesto el de trabajo.

En el transporte, el porteador cumple y renueva incesantement en el tiempo su obligación de conducir, la cual sólo se agota con e] desplazamiento hasta el lugar de destino. El tiempo desempeña aqu papel importante. Todas las prestaciones no se agotan en un momento dado, no se cumplen de una vez. La traslación de un lugar a otro 'ó. gicamente supone cierto período de tiempo, más o menos prolongado según la velocidad y la extensión del recorrido, entre el momento de comenzar y de concluir el transporte, lapso durante el cual las obli. gaciones del transportador se renuevan de una manera continua. Por esto el transportador debe cuidar, vigilar y conservar en perfecto es. tado las cosas objeto de la conducción; obligaciones éstas que se re. piten durante todo el tiempo que dure el transporte.

El C. D. C. T. expresa, que "si después de comenzado el viaje sobreviniere un obstáculo de fuerza mayor, el porteador podrá rescin. dir el contrato, o continuar desde luego el viaje por otra ruta o por la designada después de removido el obstáculo. Elegida la rescición, podrá depositar la carga en el lugar más próximo al de su destino, o retornarla al de su procedencia, y en uno y otro caso cobrará to. do el porte estipulado" (24). De acuerdo con esta norma, cuando ya ha comenzado la conducción y sobreviniere una fuerza mayor, el transportador tiene, entre otras facultades, la de rescindir el contrato. Habíamos dicho que en el transporte, como contrato tractu tempore que es, no operaba la rescición sino la terminación. La expresión que usa el código es indudablemente incorrecta, el término jurídico apropiado es aquí cesación, expiración o terminación.

De presentarse en caso previsto por la citada norma el fenómeno de la rescición, tendríamos necesariamente que aceptar las siguientes conclusiones: a) Siendo la rescición un fenómeno jurídico que no opera de "pleno derecho", "ipso-jure", sería entonces indispensable la declaración judicial al respecto. b) Las cosas deberían volver al estado que tenían antes de la celebración del contrato, habría efectos retroactivos. En la situación contemplada, por una parte, no se requiere declaración judicial, ni tampoco las cosas quedan como si no se hubiere realizado contrato alguno, puesto que como claramente dice el artículo: el porteador podrá cobrar todo el porte estipulado. Es que como ya se han cumplido determinados efectos, sería imposible deshacerlos, suponer que nada ha acontecido y negar al trans-

(24) C. D. C. T. Art. 294. portista el derecho que tiene a cobrar el porte por la conducción. $\mathrm{Pa}-$ ra que un contrato sea de ejecución diferida, no es absolutamente necesario que todas las prestaciones se continúen en el tiempo, basta, como ocurre en el transporte que algunas de las prestaciones tengan tal característica. En Chile, lo mismo que en Italia, cuando se presenta una fuerza mayor con posterioridad a la iniciación del viaje, el porteador únicamente tiene derecho a un flete proporcional al trayecto recorrido, pero de todas maneras las cosas no vuelven a su estado anterior, no se deshacen los efctos ya cumplidos.

Por lo visto, el transporte no es un contrato de ejecución instantánea sino sucesiva, operando entonces la terminación y no la rescición como dice nuestra ley.

Es de anotar que el proyecto no habla por ninguna parte de rescición.

Desde el punto de vista de su perfeccionamiento los contratos pueden ser "consensuales", "reales" y "solemnes". Es consensual el contrato, cuando para su perfeccionamiento basta el mero acuerdo de las partes. En el real es indispensable para el perfeccionamiento la entrega de la cosa. En el solemne se requiere la observancia de ciertas formalidades especiales, necesarias para la existencia misma del contrato.

La concepción de los contratos reales tiende hoy a desaparecer. La corriente que ha criticado ésta noción por antitécnica e inútil, ha sido poderosa sobre todo en el campo del derecho comercial, en donde contratos típicamente reales como la prenda, de acuerdo con la concepción tradicional del derecho civil, se consideran consensuales. Lo mismo ha pasado en el propio campo del derecho civil, en contratos como el mutuo y el depósito, antes de carácter real, actualmente concebidos como consensuales. Es que "eso de tener que entregar, la cosa para que surja la obligación de restituirla es innecesario ya que el arrendatario también se obliga a restituir sin que el arrendamiento de cosas sea contrato real. Por otra parte, es artificioso y antitécnico, que la entrega de la cosa, que debe ser la ejecución de la obligación nacida del contrato, sea considerada como elemento de formación del mismo. La entrega es consecuencia del contrato no factor de integración de él" (25).

La doctrina extranjera ha estado de acuerdo en tratar al transporte de personas como un contrato consensual. Sobre este aspecto ha existido un criterio uniforme. No ha sucedido lo mismo con el trans(25) Prof. Eudoro González G. Revista Estudios de Derecho No 38. Pág. 189. 
porte de cosas, ya que determinados autores han afirmado que este contrato es real, pero la tesis predominante al respecto ha sostenido la consensualidad del transporte de cosas.

Para quienes piensan que el transporte de cosas es real, el contrato sólo se perfeccionaría por la entrega de la cosa al porteador, no naciendo para las partes antes de la entrega, obligaciones de ningusı clase.

No habiendo diferencia de naturaleza entre el transporte de personas y el de cosas, no se ve por qué el primero sea consensual y el segundo real. La opinión doctrinal más generalizada, ha creido que el contrato es consensual porque el remitente tiene acción para compeler al transportista a desplazar al lugar de su destino los objetos que deban trasladarse, y en virtud de esta acción pueda obligarlo a recibir y conducir las cosas objeto del transporte, es decir, la acción puede preceder a la entrega. Cuestión que sería absolutamente imposible en los contratos reales, en los cuales si no hay entrega no hay contrato, no surgiendo, por tanto, obligaciones para las partes, la acción aquí no puede preceder a la entrega.

Piensan en la consensualidad del transporte de cosas, entre otros, Ascarelli, Garrigues, Mossa, Malagarriga, Obarrio y el tratadista Argentino Hécor Cámara.

No han faltado quienes hayan aseverado que el transporte en general, es un contrato solemne. En el transporte de cosas esta posición ha sido fundada en el hecho de que las partes, para demostrar la existencia y modalidades del contrato, suscriben un documento de vital importancia denominado "carta guía", "carta de porte", "conocimiento" o "póliza de embarque". En el transporte de personas se ha pretendido ver en el "tiquete", "billete de asiento" o "aposentamiento" una solemnidad esencial al contrato. Esta tesis tampoco ha tenido mayor éxito porque universalmente el "tiquete" y la "carta de porte" son simples medios de prueba, mas no solemnidades propias del contrato, no se trata pues, de solemnidades "ad substantiam actus" sino "ad probationem". La ausencia de dichos documentos no conlleva la nulidad o la inexistencia del contrato, y éste se puede demostrar por cualquiera de los medios probatorios reconocidos por el derecho. Esta concepción es compartida por la legislación del país, en donde se dispone que "en defecto de carta de porte, la entrega de la carga podrá justificarse por cualquiera de los medios que indica el art. 266" (26). Por su parte, el art. 266 expresa que "el contrato se

(26) C. D. C. T. Art. 278. prueba con la carta de porte, y por cualquiera de los medios probatorios que sanciona este código y el judicial".

$\mathrm{El}$ doctor Alberto $\mathrm{H}$. Torres afirma que en Colombia el contrato de transporte es real, y en apoyo de su opinión cita el art. 281 del código, disposición según la cual "no verificándose la entrega de los efectos en el tiempo y paraje convenidos, podrá el porteador solicitar la rescición del contrato y el pago de la mitad del porte estipulado, pero si prefiere llevar a cabo la conducción el cargador deberá pagarle el aumento de costos que le ocasionare el retardo de la entrega". Para el Doctor Torres la regla de este artículo "está indicando que el contrato queda insubsistente, no produce obligaciones, que es precisamente lo que caracteriza los contratos reales el hecho de no producir obligaciones antes de la entrega" (27). Y agrega el mismo autor, citando al español Manresa y Navarro "para que una cosa sea es menester entregarla al porteador, o conductor, en este sentido la entrega de la cosa por parte del cargador es ineludible". Para que una cosa sea transportada obviamente se necesita que sea entregada al transportador, esto es un axioma, pero para que exista el contrato de transporte como fuente de obligaciones, basta el mero acuerdo de las partes sobre los elementos constitutivos de la operación jurídica. Una cosa es que el objeto para ser transportado debe ser entregado, y otra muy distinta que antes de la entrega los contratantes se vinculen por el mero consentimiento, de una manera consensual.

Haciendo caso omiso de la mala redacción que tiene el articulo 281, como más adelante observaremos, y sin tener en cuenta lo que el nombrado expositor piense al respecto, las consideraciones que vamos a hacer, nos demostrarán de una manera fehaciente, que la posición del Dr. Torres carece en absoluto de basamento frente al derecho positivo colombiano.

El método seguido por el legislador en materia civil nos está confirmando el carácter consensual de este contrato. El transporte ha sido colocado en el C. C. en el título correspondiente al arrendamiento, y éste es un contrato consensual aunque verse sobre bienes inmuebles.

Según el C. D. C. T. "el cargador está obligado a entregar las mercaderías al porteador bien acondicionadas, y en el tiempo y lugar convenidos, y a suministrarle los documentos necesarios para la libre circulación de la carga" (28). A su vez, el porteador está obligado a

(27) Revista trimestral de derecho comercial No 2829

C. D. C. T. Art. 279 
"recibir las mercaderías en el tiempo y lugar convenidos, a cargarlas según el uso de personas inteligentes, y a emprender y concluir el viaje en el plazo y por el camino que señale el contrato" (29).

De acuerdo con los transcritos artículos el transporte impone obligaciones a las partes antes de la entrega de la cosa, luego no es real sino consensual.

Apartándonos de todas las argumentaciones expuestas, existe una que por sí sola despeja cualquier duda al respecto. Efectivamente, en nuestra legislación el transporte "se perfecciona por el solo cosentimiento expreso o tácito de las partes" (30). Ante norma tan clara, huelga cualquier comentario, y si algunas reflexiones diferentes hicimos, fue con el único fin de probar que aunque no existiese disposición expresa al respecto, el transporte siempre sería consensual de acuerdo con nuestro sistema legal imperante.

Si desde el punto de vista de la legislación vigente en el país el hecho de que el transporte es un contrato consensual no admite dudas, en el proyecto tampoco es discutible esta opinión, porque para éste el "transporte se perfecciona, por el solo acuerdo de las partes y se prueba por la carta de porte o el tiquete, según que se trate de cosas o de pasajeros, o por cualquiera de los medios de prueba admitidos en la legislación procesal civil" (31).

A veces el consentimiento en el transporte no se manifiesta do una manera expresa, sino que se presume. La persona que toma un bus y deposita el porte, nada manifiesta exteriormente, se dice entonces que se ha celebrado un contrato "tácito" de transporte, lo que no quiere decir que no haya consentimiento, simplemente pasa que este se deduce.

El transporte ha sido considerado como un contrato "por adhesión". Saleilles quien critica esta noción es el autor de la expresion, él los llamó contratos "de adhesión", actualmente se les denomina tal vez con más propiedad contratos "por adhesión". Ni el C. C. Frances ni el Colombiano reglamentan este contrato, y ello es lógico porque se trata de un fenómeno social nacido como consecuencia de importantes transformaciones sociales y económicas, posteriores a la expedición del código Napoleónico.

El contrato por adhesión se distingue por su generalidad, permanencia y rigidez. La Corte en fallo del 12 de diciembre de 1936 ai reconocer la realidad de dichos contratos, ve en ellos estas caracteris-

(29) C. D. C. T. Art. 290.

(31) P. D. C. D. C. Art. 803 ticas: a) La oferta, dirigida a personas indeterminadas, tiene un carácter general y permanente, y se encuentra frecuentemente impresa, en forma de contrato-típo, para que sea aceptada o rechazada en bloque. b) La oferta emana de quien tiene un monopolio de hecho o de derecho. c) Estos contratos constan de muchas cláusulas, de diticil lectura cuidadosamente redactados en interés de quien hace la oferta y cuya trascendencia generalmente no aprecia el adherente. d) No existen prolegómenos.

Sobre la existencia de los contratos por adhesion, se nan planteado dos teorías, la reglamentaria y la contractual. Para los partidarios de la tesis reglamentaria, la sola voluntad del oferente crea ia obligacion, determina el contrato y sus efectos. La voluntad del adherente es una cuestión accesoria que no influye en la formacion del acto. La segunda teoria, por el contrario, defiende la estructura contractual de esta figura, sosteniendo que al fin $\mathrm{y}$ al cabo existe un acuerdo de voluntades. Quien adhiere a la minuta elaborada de antemano, conviene y acepta con lo que el oferente ya tiene impreso y reglamentado con anterioridad.

Parece que los contratos por adhesión sí son auténticos contratos, porque como asevera la corte en sentencia del 18 de Sepptiembre de 1947 "si la voluntad del adherente no da la medida de la obilgación, en cambio de ella depende lo único que es esencial; la existencia misma de la obligación". La adhesión, como se ha archo, es simplemente una de las formas de expresar el consentimiento. Estamos, pues, ante un fenómeno jurídico real que no podría desconocerse, lo importante en esta materia es evitar los abusos que con los contratos por adhesión puedan cometer ciertas empresas.

Tanto los sostenedores de la tesis reglamentaria, como los defensores del criterio contractualista, son partidarios de favorecer la parte débil. Los primeros dicen que se debe proteger a quien aúhiere a la manifestación unilateral de la voluntad reglamentaria que es la que se impone. Los contractualistas manifiestan que hay que socorrer al contratante que conviene por adhesión.

A los contratos en mención se les han aplicado los siguientes principios clásicos. a) Las cláusulas ambiguas extendidas o dictadas por la parte oferente, se interpretan en su contra. b) Debe prevalecer la intención sobre lo escrito. c) Entre dos cláusulas íncompatibles, el juez debe escoger la que proteja al adherente.

A pesar de que la opinión más común confiere al transporte el carácter de contrato por adhesión, nos parece que si tenemos en cuenta las modernas nociones sobre economia dirigida e intervencionismo 
estatal, es éste un contrato "dirigido". En ningún país, teóricamente hablando, las empresas de transporte son omnímodas e imponen al público de una manera libérrima sus condiciones. Hl estado interviene a diario con el objeto de limitar esas desaforadas ambiciones económicas de las grandes empresas, tratando así de favorecer a quienes por múltiples motivos se encuentran en situación desventajosa. Las empresas no pueden libremente imponer tarifas, determinar cupos, en fin, no deben violar la muy abundante legislación de orden público que internacionalmente existe sobre los transportes. Que en determinados países las cosas no sucedan así, o que en la práctica el estado contemple con tranquilidad y hasta con placidez la infraccion de la ley y la imposición del más fuerte, no lo negamos. Yero de todas maneras tales anomalías, injustificables desde todo punto de vista, no pueden ser un obstáculo definitivo para poder ambicionar, al menos, un poco más de justicia.

Entre el contrato por adhesión y el dirigido existen disimilitudes de fondo. Estas nociones son indiferentes. En el contrato por adhesión una parte, la adherente, acepta y conviene con lo que el oferente tiene ya previsto y reglamentado de antemano, siendo entonces la voluntad de quien hace la oferta la que en principio impone las condiciones del contrato y desempeña generalmente el papel de la parte económicamente poderosa. En el contrato dirigido el problema es distinto. Ya no se trata de adherir a la reglamentación y condiciones previstas por el oferente. En este caso todas las partes contratantes están obligadas a pactar bajo ciertas condiciones preestablecidas por el ordenamiento jurídico, en normas que por ser de orden público son inderogables por la voluntad de los particulares. Ya no es entonces la voluntad del oferente la que determina las condiciones del contrato, pues éstas han sido ya impuestas de una manera definitiva por el ordenamiento jurídico, al cual necesariamente tienen que plegarse las partes en relación con las condiciones del contrato. Precisamente, por el hecho de que estos contratos tienen que amoldarse a ciertos presupuestos legales esenciales y de obligatoria aceptación, han sicio llamados también contratos "dictados".

La concepción de los contratos dirigidos paulatinamente va absorviendo la noción de los contratos por adhesión. A medida que aumenta el intervencionismo estatal, se amplía el ámbito de aplicación de los primeros.

Finalmente, y para terminar lo relativo a la clasificación del transporte, conviene saber que por su importancia se ha sostenido que es éste uno de los contratos "fundamentales" del derecho comercial. 